\title{
APONTAMENTOS SOBRE COOPERAÇÃO E CRÍTICA NAS FILOSOFIAS DE R. RORTY E J. HABERMAS
}

\begin{abstract}
Resumo
A comunicação pretende sinalizar que o debate entre a "filosofia sem espelhos", de Richard Rorty e a teoria do agir comunicativo, de Jürgen Habermas, pode ser entendido como exemplo ímpar de crítica e cooperação na busca da verdade filosófica. A estratégia de apresentação se configura em dois procedimentos distintos: Em um primeiro momento proceder-se-á à demarcação sumária da presença do pensamento de Habermas em textos característicos de Rorty e vice-versa. A seguir, será empreendida uma tentativa visando mostrar que a relação entre o pensamento de Rorty e o de Habermas é dialética, isto é, ao mesmo tempo crítica e cooperativa. O objeto principal do debate entre ambos tem a ver, principalmente, com a correta interpretação da virada linguística efetuada na filosofia contemporânea: até que ponto ela implica o abandono puro e simples da teoria da modernidade e do conceito de racionalidade, de Kant, o que implicaria uma verdadeira autodemissão da filosofia? Qual deve ser o critério do novo discurso filosófico: a comensurabilidade científica ou a incomensurabilidade de um não-consenso edificante?
\end{abstract}

Palavras-chave: Filosofia Contemporânea. Virada Linguística. Teoria do Agir Comunicativo. Contextualismo Radical.

\begin{abstract}
The communication aims to signal that the debate between Richard Rorty's "philosophy without mirrors" and Jürgen Habermas's theory of communicative action can be understood as a unique example of criticism and cooperation in the search for philosophical truth. The presentation strategy is set up in two distinct procedures: In a first moment, the presence of Habermas's thought in Rorty's texts and vice versa will be summarized. Next, an attempt will be made to show that the relationship between Rorty's and Habermas's thoughts is dialectical, that is, at the same time critical and cooperative. The main object of the debate between the two has to do mainly with the correct interpretation of the linguistic turn made in contemporary philosophy: to what extent does it imply the abandonment of Kant's theory of modernity and the concept of rationality, pure and simple. would imply a true self-declaration of philosophy? What should be the criterion of the new philosophical discourse: the scientific commensurability or the incommensurability of an edifying non-consensus?
\end{abstract}

Keyword: Contemporary Philosophy. Linguistic Turnaround. Theory of Communicative Action. Contextualism Radical.

\section{INTRODUÇÃO}

Gostaria de salientar, inicialmente, que tomo como ponto de partida uma constatação quase unânime: o fato de que as obras "O espelho da natureza" (1979) e "Contingência, ironia e solidariedade" (1989), de Richard Rorty, bem como os textos de Jürgen Habermas: "Teoria do agir comunicativo" (1981) e "Verdade e justificação" (1999), se 
destacam entre as tentativas filosóficas contemporâneas mais radicais e influentes que visam, não somente a crítica da filosofia, mas também a sua reconstrução após a assim chamada "queda da metafísica" (Adorno).

Meu principal objetivo consiste em mostrar, mediante enfoque de pontos relevantes que a elaboração dessas duas filosofias paradigmáticas da atualidade constitui exemplo único de cooperação e crítica entre dois pensadores que, apesar de seguirem caminhos distintos, se empenham em levar adiante, cada um à sua maneira, o ditame hegeliano, segundo o qual, a tarefa principal da filosofia consiste em apreender a respectiva contemporaneidade mediante pensamentos ${ }^{1}$. E no desempenho dessa tarefa ambos tentam aprender um do outro, não somente dos pretensos acertos, mas também dos erros. E isso equivale a dizer que o nível teórico atingido por um deles influenciou hermeneuticamente o do outro e vice-versa.

\section{GÊNESE DA RELAÇÃO COOPERATIVA E CRÍTICA ENTRE AS FILOSOFIAS DE RORTY E HABERMAS}

\subsection{PRESENÇA DE HABERMAS NOS TEXTOS DE RORTY}

É necessário iniciar pela apresentação da presença de Habermas nos textos de Rorty por uma simples razão: Rorty descobre Habermas antes de ser descoberto por este, ao menos nos textos escritos por ambos. Por essa razão Habermas aparece no pensamento de Rorty antes mesmo de Rorty fazer parte da grande lista dos autores com os quais Habermas estabelece relações de acoplagem dialógica e crítica. A aparição de Habermas em textos de Rorty se dá em 1979, no Cap. VIII do Espelho da natureza. Este capítulo trata precisamente da "filosofia sem espelho" que deve entrar em vigor após a desconstrução do paradigma mentalista. ${ }^{2}$

Neste texto Rorty (1981), se detém basicamente em dois elementos fundamentais da teoria habermasiana e apeliana, a saber, em primeiro lugar, a "hermenêutica quasetranscendental" formulada por Habermas em 1968 no livro Conhecimento e interesse, portanto durante a fase que antecede a guinada pragmática. Em segundo lugar, ele se manifesta quanto à pragmática universal habermasiana escrita em 1976. Esse fato permite aventar a hipótese de que ideias e conceitos de Habermas anteriores à publicação da teoria do agir comunicativo

\footnotetext{
${ }^{1}$ Nota: Richard Rorty faleceu em 2007.

${ }^{2}$ Cf. RORTY, R. Philosophy and the mirror of nature. Princeton: University Press, 1979. Na presente comunicação é utilizada a segunda edição da tradução dessa obra para o alemão: Id. Der Spiegel der natur: Eine Kritik der philosophie. Frankfurt/M.: Suhrkamp, 1981.
}

LOGEION: Filosofia da informação, Rio de Janeiro, v. 5, 2018, Edição Especial, p.97-104 
tiveram influência hermenêutica no trabalho rortyano, seja na desconstrução do espelho da natureza, seja na construção de uma nova filosofia sem espelho.

E esta influência se aprofunda, se alarga e se multiplica no decorrer dos anos 80. Em um texto editado por Guidens et al. (1988), intitulado Habermas and Modernity, Rorty faz um excelente comentário crítico da obra habermasiana e tenta aproximar o pensamento habermasiano do de J. F. Lyotard (RORTY, 1988). Entretanto, é no pequeno, e, ao mesmo tempo, grande e decisivo livro de Rorty intitulado Contingência, ironia e solidariedade que a presença de Habermas se manifesta com maior intensidade: Ele passa a ser, ao lado de Heidegger, Marx e Dewey, não somente um contraponto estimulante, mas também um foco inspirador para Rorty (1995). ${ }^{3}$

\subsection{RORTY NOS TEXTOS DE HABERMAS}

Rorty irrompe na obra habermasiana em 1980, um ano antes da publicação da Teoria do agir comunicativo, em uma Réplica escrita por Habermas a fim de responder a objeções contra o conceito de agir comunicativo (Cf. HABERMAS, 1984, p. 561).

Tais menções se limitam, no entanto, ao "desconstrutivismo de Rorty e fazem referências ao Espelho da natureza. Habermas se apóia nelas para afirmar que a filosofia não pode mais, a partir de agora, dirigir-se ao mundo, à natureza, à história ou à sociedade assumindo a posição de um saber totalizador (HABERMAS, 1981, p. 15-16).

No entanto, a irrupção rortyana se torna, a partir daí cada vez mais frequente e avassaladora: Em 1981, numa conferência intitulada "A filosofia como intérprete e guardadora de lugar", apresentada em um Congresso organizado pela Associação hegeliana (Hegel Vereinigung) ${ }^{4}$, Habermas se dedica à discussão aprofundada de temas rortyanos: pró e contra! Convém destacar, todavia, um segundo texto intitulado "Verdade e justificação" no qual Habermas (1999) submete a sua teoria do agir comunicativo a uma profunda revisão à luz de problemas levantados por um naturalismo mais severo e pelo realismo epistemológico. O quinto capítulo desta obra, igualmente intitulado "Verdade e justificação, contém um diálogo crítico

\footnotetext{
${ }^{3}$ Cf. Id. Contingence, irony, and solidarity. Cambridge: University Press, 1989. No presente trabalho é utilizada a terceira edição da versão para o alemão realizada por: Christa Krüger. Id. Kontingenz, Ironie und Solidarität. Frankfurt/M: Suhrkamp, 1995.

${ }^{4} \mathrm{O}$ texto que serviu de base a essa conferência foi publicado em 1983. Cf. tradução para o português (Consciência moral e agir comunicativo) realizada por Guido A. de Almeida e publicada pela Editora Tempo Brasileiro em 1989.
}

LOGEION: Filosofia da informação, Rio de Janeiro, v. 5, 2018, Edição Especial, p.97-104 
com a guinada pragmática de Rorty, que serve de inspiração, correção e contraponto a Habermas.

\section{CONVERGÊNCIAS E DIVERGÊNCIAS ENTRE RORTY E HABERMAS À LUZ DE UMA QUESTÃO CENTRAL}

Nesse ponto pretendo apresentar alguns resultados da relação dialética entre Habermas e Rorty lançando mão de uma questão que considero central em suas respectivas teorias: o destino da filosofia após a ruptura do espelho da natureza. Gostaria de sublinhar, no entanto, que o fato de orientar as considerações muito mais pela teoria habermasiana do que pela rortyana não significa que considero os argumentos habermasianos sempre mais convincentes do que os de Rorty. Significa apenas que, devido a limitações de minha parte, me sinto relativamente mais à vontade em terreno habermasiano.

\subsection{O DESTINO DA FILOSOFIA APÓS A RUPTURA DO ESPELHO DA NATUREZA.}

O pressuposto da crítica rortyana à filosofia tradicional pode ser resumido da seguinte maneira: a maior parte de nossas convicções filosóficas é dominada por imagens e metáforas, não por frases ou proposições. E a filosofia tradicional fica presa à imagem de uma consciência que funciona como um grande espelho capaz de refletir diferentes tipos de representações mais ou menos acuradas. E esse espelho tem de ser analisado com o auxílio de métodos apriorísticos. Por isso, a filosofia tem de ser, segundo Rorty, revista.

E ele escolhe como ponto de partida para sua revisão da filosofia as críticas desenvolvidas por Heidegger, Wittgenstein e Dewey que são, segundo ele, os pensadores mais importantes do século XX porque rompem com a concepção kantiana, segundo a qual, a filosofia constitui uma ciência fundamental baseada em representações da consciência.

Por conseguinte, aos olhos de Rorty a rejeição da filosofia especular moderna proposta por seus mentores filósofos constitui uma verdadeira "demissão por justa causa" (RORTY, 1984, p. 16).

É interessante observar que Rorty, ao menos na época da redação do Espelho da natureza (1979), não encara a demissão da filosofia sistemática com espírito derrotista. Antes, pelo contrário, ele pensa que, a partir do momento em que deixamos de considerar a filosofia 
como um empreendimento de construção sistemática, é possível desenvolvê-la como uma atividade terapêutica, formadora e educativa. E nesse novo contexto a filosofia passa a desempenhar dois papéis distintos, a saber:

- O papel de um diletante bem informado, de um "polipragmático" e de um mediador socrático capaz de criar mediações hermenêuticas e traduções entre vários tipos de discurso. Trata-se aqui da figura do intelectual formador ou educador que vai, constantemente, em busca de modos mais novos e interessantes de descrever as coisas (RORTY, 1984, p. 345).

- De outro lado, a filosofia também pode assumir o papel de um inspetor da cultura que conhece os fundamentos comuns a todos e que, na qualidade de rei-filósofo, sabe o que os outros fazem na realidade apesar de eles mesmos não saberem porquanto ele conhece o contexto intransponível (unvordenklich) das formas, da linguagem e da consciência.

É importante destacar que, na concepção de Rorty, o "mediador polipragmático" não utiliza por via de regra os discursos convencionais das ciências cujo critério de validade se estriba unicamente na comensurabilidade. Para entender isso convem lembrar uma distinção importante entre discurso normal e discurso não normal que Rorty leva a cabo mediante uma generalização da distinção introduzida por Thomaz Kuhn entre "ciência normal" e "ciência revolucionária” (RORTY, 1984, p. 348).

- O discurso normal é comensurável porque se desenvolve em um sistema de convenções reconhecidas em geral, as quais estabelecem preliminarmente o que pode e o que não pode valer como bom argumento, como boa contribuição, como boa crítica (RORTY, 1984, p. 348-349). O seu produto é sempre ciência (episteme), isto é, enunciados que podem ser reconhecidos e aceitos por sua racionalidade.

- Já o discurso extraordinário é incomensurável porquanto dele tomam parte pessoas que não reconhecem ou simplesmente ignoram tais convenções. Por isso, o seu produto é completamente indeterminado, ou seja, pode conter tudo ou nada, o absurdo, o imprevisível, uma revolução, etc.

Fica claro, pois, o destino de uma filosofia demitida por justa causa, desprovida de espelho refletor de ideias e sem fundamento último: ela é constrangida a abandonar a posição privilegiada que ocupava em um tribunal destinado a julgar a priori a cultura em geral e as pretensões cognitivas das ciências e da própria metafísica.

Esta conclusão aguçou naturalmente a curiosidade de Habermas em relação à filosofia de Rorty. E o inspirou, certamente, a caracterizar a filosofia como guardiã da racionalidade e como intérprete das esferas da vida. 
Habermas formula inicialmente a seguinte questão geral: será que a crítica ao fundamentalismo, que é desenvolvida por Rorty, implica necessariamente o abandono da teoria da modernidade, de Kant?

Ele prefere não formular uma resposta direta a essa questão. Configura, ao invés disso, três grandes etapas da crítica radical à filosofia que tem início em Hegel, passa por Strawson, Paul Lorenzen e Karl Popper e culmina na crítica radical de Paul Feyerabend, M. Foucault, Derrida e Rorty.

Ele constata que na terceira etapa, a de uma filosofia sem espelhos, a crítica filosófica simplesmente abandona o horizonte no qual se movia a filosofia da consciência.

Ante tal cenário, Habermas levanta a seguinte questão: em que sentido as novas ideias da hermenêutica e do pragmatismo devem ser entendidas?

- Como uma renúncia total à pretensão da razão inerente à filosofia, o que equivaleria a uma demissão do papel da filosofia?

- Ou como um novo paradigma, o qual, mesmo que substitua o jogo de linguagem mentalista da filosofia da consciência, não abroga os modos de fundamentação da filosofia da consciência? (RORTY, 1984).

No que tange ao modo rotyano de demissão da filosofia, que culmina na passagem para um discurso extraordinário, incomensumerável, cujas orientações são sempre controvertidas, Habermas afirma que este tipo de crítica aglutina em um só corpo todas as qualidades que a filosofia adquiriu através das suas sucessivas demissões críticas.

No meu entender, é possível resumir a crítica de Habermas ao modo como Rorty interpreta a autodemissão da filosofia em dois pontos:

Primeiro ponto: Habermas está convencido da consistência dos argumentos elaborados por Rorty.

Segundo ponto: Ele não aceita a conclusão de Rorty, segundo a qual, a filosofia tem de abandonar não somente o papel de indicadora do lugar das ciências e de juiza da cultura, mas também o de guardiã (Hüter) da racionalidade. Habermas pensa que a conclusão rortyana levaria a uma renúncia pura e simples das pretensões racionais que acompanham a filosofia desde a sua origem.

Por esta razão, ao final de sua narrativa dos principais lances históricos da autocrítica de uma filosofia demissionária, Habermas contrapõe-se a todas as formas de autodemissão ao defender a tese de que a filosofia - mesmo destituída das funções de um juiz que tem o poder de indicar as posições a serem ocupadas pelas ciências - pode e deve continuar mantendo pretensões de validade. Mesmo que para isso ela tenha de assumir as funções mais LOGEION: Filosofia da informação, Rio de Janeiro, v. 5, 2018, Edição Especial, p.97-104 
modestas de um intérprete hermenêutico e pragmático do mundo da vida e de um guardião da racionalidade (RORTY, 1984, p. 11-12).

\section{CONCLUSÃO.}

Tendo em vista as considerações acima desenvolvidas, considero adequado finalizar a presente comunicação chamando a atenção para o fato de que os processos de aprendizagem recíprocos, que levaram Rorty e Habermas a uma cooperação teórica e crítica intensa, não anularam as diferenças que marcam o pensamento de ambos.

Porquanto, se é verdade que tanto Rorty como Habermas se empenham em seguir o ditame hegeliano que os obriga a apreender o seu tempo em pensamentos filosóficos, é verdade também que existe uma distância entre ambos, a qual é do tamanho da distância que separa um discurso teórico comensurável de outro não comensurável. Dito de outra forma: é a distância que separa um discurso que pretende ser apenas edificante e formador de outro discurso que se empenha, além disso, em fazer jus a pretensões de validade e em solucionar problemas da convivência humana. 


\section{REFERÊNCIAS}

HABERMAS, J. Theorie des kommunikativen Handelns, 3. ed., Frankfurt/M.: Suhrkamp, 1981.

. Moralbewusstsein und kommunikatives Handeln. Frankfurt/M.: Suhrkamp, 1983. Vorstudien und Ergänzungen zur Theorie des kommunikativen Handelns.

Frankfurt/M.: Suhrkamp, 1984.

. Wahrheit und Rechtfertigung: philosophische aufsätze. Frankfurt/M.: Suhrkamp, 1999.

RORTY, R. Der Spiegel der Natur: Eine Kritik der Philosophie. 2. ed. Frankfurt/M.: Suhrkamp, 1984. Tradução de: Michael Gebauer.

. Kontingenz, Ironie und Solidarität. 3. ed. Frankfurt/M.: Suhrkamp, 1995.

Tradução de: Christa Krüger.

Philosophy and the mirror of nature. Princeton: University Press, 1979.

. Habermas y lyotard sobre la posmodernidad. In: GUIDDENS, A. et al. Habermas y

la modernidad. Madrid: Catedra, 1988, p. 253-276. 